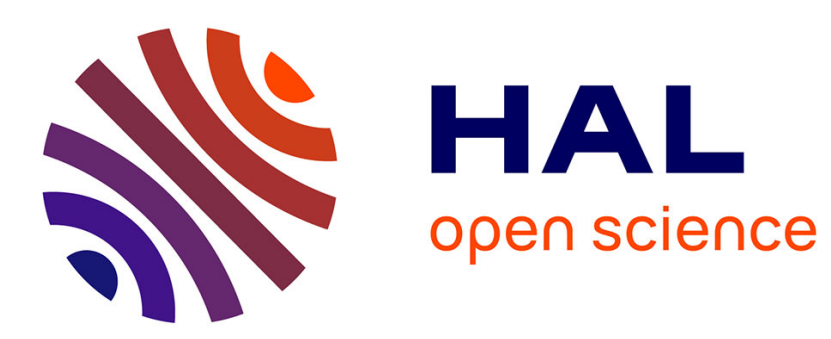

\title{
An Empirical Many-Body Potential for B2 FeAl
}

R. Besson, A. Fraczkiewicz, M. Biscondi

\section{To cite this version:}

R. Besson, A. Fraczkiewicz, M. Biscondi. An Empirical Many-Body Potential for B2 FeAl. Journal de Physique IV Proceedings, 1996, 06 (C2), pp.C2-47-C2-52. 10.1051/jp4:1996206 . jpa-00254184

\section{HAL Id: jpa-00254184 https://hal.science/jpa-00254184}

Submitted on 1 Jan 1996

HAL is a multi-disciplinary open access archive for the deposit and dissemination of scientific research documents, whether they are published or not. The documents may come from teaching and research institutions in France or abroad, or from public or private research centers.
L'archive ouverte pluridisciplinaire HAL, est destinée au dépôt et à la diffusion de documents scientifiques de niveau recherche, publiés ou non, émanant des établissements d'enseignement et de recherche français ou étrangers, des laboratoires publics ou privés. 


\title{
An Empirical Many-Body Potential for B2 FeAl
}

\author{
R. Besson, A. Fraczkiewicz and M. Biscondi \\ Ecole des Mines, Centre S.M.S., URA 1884 du CNRS, 158 Cours Fauriel, 42023 Saint-Etienne cedex 2, \\ France
}

\begin{abstract}
Studies of grain boundaries may be helpful in understanding the brittleness of the B2 ordered alloy FeAl. To this end, an interatomic potential is proposed, lying on a modified Embedded-Atom Method. This method, rather similar to that used for semiconductors, involves a 3-body non central term in the energy, making it possible to describe the strongly directional effects in FeAl. A great number of zero temperature bulk and defect properties are correctly reproduced for $\mathrm{Fe}$ and $\mathrm{Al}$ as well as for the alloy, indicating that the potential is probably a good tool for molecular statics simulations. As a first application, the structure of the $\Sigma 5[100] 37^{\circ}$ tilt grain boundary is determined.
\end{abstract}

\section{INTRODUCTION}

Intermetallic compounds, owing to their potential ability to replace other materials, form the subject of an increasing amount of studies. Among these, FeAl takes up an interesting place, in regard of its quite high specific stiffness. Unfortunately, it is impaired by a strong intergranular brittleness making its elaboration uneasy and its industrial use hazardous. As is the case for many intermetallics, addition of a small amount of boron changes its fracture mode into transgranular cleavage [1]. Therefore, current researches aim at understanding the reasons for this brittleness and the role of $\mathrm{B}$. Within the scope of these researches, the present paper describes the fitting of an interatomic potential for the $\mathrm{Fe}-\mathrm{Al}$ system, the final purpose being the study of grain boundaries.

\section{CHOICE OF POTENTIAL}

The Fe-Al system is described by such a complexe phase diagram that it is totally hopeless to attempt to determine a potential that could describe the properties of compounds with any composition. Our final aim being to calculate the properties of grain boundaries in nearly stoichiometric FeAl (in the range of compositions between 38 and 50 at. $\% \mathrm{Al}$ ), it seems natural to focus the fit on the characteristics of this precise monocrystalline compound. However, the segregation phenomena occurring at interfaces are bound to change the local composition dramatically. In such conditions, the potential should be able to describe these pure elements too

Moreover, the $\mathrm{Fe}-\mathrm{Al}$ system displays strongly directional bonds, which is examplified by a negative Cauchy discrepancy $\mathrm{C}_{12}-\mathrm{C}_{44}$. This feature rules out any as-such use of the Embedded Atom Method (E.A.M.) for our purpose, since this procedure cannot allow for it [2]. This roughly means that E.A.M. cannot properly describe covalent effects, in which the electronic charge density is concentrated on particular directions. In fact, classical E.A.M.-type expressions can be derived in two ways, the first of which [3] makes it valid for normal metals (with very little directional bonding) and the second one [4] rests on a simple tight-binding method well suited for transition metals. The case of FeAl is situated quite intermediately between the two preceding ones: it is a mixture of a simple and a transition metal, and the electronic structure shows a strong s-d hybridization, responsible for its quite unusual behaviour. Faced with such a system, the most satisfactory attitude would doubtlessly be to get an analytical expression on a 
theoretically firm basis. To this aim, a potential based on the tight-binding bond model has recently been derived [5]. But the calculation of configurational energy and forces is too heavy for us to use it in our grain boundaries calculations. Thus we have to confine to a much simpler semi-empirical model, which is more easily tractable.

Keeping in mind the inefficiency of the classical E.A.M., we turned to potentials designed for semiconductors, although it has not been so far a very usual procedure to describe metallic systems. The most simple ones involve an additional 3 body non-central term [6], which was initially introduced as an angularly dependent correction for the density over a site $[2,7]$. However, as the system of interest is metallic, we preferred to confine to a form of potential already successfully tested in such a context and chose an expression first proposed on more empirical grounds [8] and already known to be efficient for several elements (among which $\mathrm{Cr}$ also displays a negative Cauchy discrepancy). Following these authors, we thus write the energy of an assembly of atoms $i$ as:

$$
E_{i}=\sum_{i}\left[F_{i}\left(\rho_{i}\right)+\frac{1}{2} \sum_{j \neq i} V_{i j}\left(r_{i j}\right)+\alpha_{i} Y_{i}^{2}\right] \text {, where } \rho_{i}=\sum_{j \times i} f_{j}\left(r_{i j}\right)
$$

$F_{i}$ can be regarded as the so-called embedding function (although its significance is quite dubious), $\rho_{\mathrm{i}}$ is the induced density over site $\mathrm{i}, \mathrm{V}_{\mathrm{ij}}$ is a pair potential classically collecting elsewhere ill-described interactions (exchange and correlation,...) and $\alpha_{i}$ is a parameter supposed to depend in a complex way on the local composition of the alloy and to contain all that information about directionality which is not taken into account by the first two classical terms.

Moreover, $\mathrm{Y}_{\mathrm{i}}^{2}=\sum_{\alpha, \beta}\left(\lambda_{\mathrm{i}}^{\alpha \beta}\right)^{2}-\frac{1}{3} \operatorname{tr}\left(\overline{\overline{\lambda_{\mathrm{i}}}}\right)^{2}$ is the second invariant of $\overline{\bar{\lambda}}$, with

$$
\lambda_{\mathrm{i}}^{\alpha \beta}=\sum_{\mathrm{j} \neq \mathrm{i}} \mathrm{f}\left(\mathrm{r}_{\mathrm{ij}}\right) \frac{\left(\mathrm{r}_{\alpha}^{\mathrm{j}}-\mathrm{r}_{\alpha}^{\mathrm{i}}\right)\left(\mathrm{r}_{\beta}^{\mathrm{j}}-\mathrm{r}_{\beta}^{\mathrm{i}}\right)}{\left(\mathrm{r}_{\mathrm{ij}}\right)^{2}}
$$

In fact, $Y_{i}^{2}$ can be recast to yield a more explicit 3-body expression:

$$
Y_{i}^{2}=\sum_{\substack{i \neq i \\ k \neq i}} f\left(r_{i j}\right) f\left(r_{i k}\right)\left(\cos ^{2} \theta_{i j k}-\frac{1}{3}\right)
$$

The physical interpretation of $\overline{\bar{\lambda}}$ rests on Kanzaki forces [9], but it is also possible to notice that its form mimics that of a d orbital.

\section{FITTING PROCEDURE}

Firstly, two potentials were calculated for pure elements: they reproduce well-known zero temperature properties: sublimation energy, lattice parameter and the three cubic elastic constants. The next step consisted in fitting a FeAl potential, derived from those calculated for the pure metals, through the addition of an $\mathrm{Fe}-\mathrm{Al}$ pair potential. This alloy potential was tested relatively to perfect lattice and defect properties of $\mathrm{FeAl}$. Finally, we also briefly studied the behaviour of the potential in an $\mathrm{Fe}_{3} \mathrm{Al}$ structure.

We only give here the analytical expressions used. The corresponding graphs are presented on fig. 1. Numerical values of parameters for pure elements as well as for the alloy are collected in appendix.

\subsection{Pure elements}

The pair potential is taken from [10]: $\mathrm{V}(\mathrm{r})=\psi(\mathrm{r})-\psi\left(\mathrm{D}_{\mathrm{p}}\right)+\frac{\mathrm{D}_{\mathrm{p}}}{20}\left[1-\left(\frac{\mathrm{r}}{\mathrm{D}_{\mathrm{p}}}\right)^{20}\right] \psi^{\prime}\left(\mathrm{D}_{\mathrm{p}}\right)$,

where $\psi(r)=\psi_{0}[\exp (-2 \gamma(r-t))-2 \cdot \exp (-\gamma(r-t))]$ is a Morse potential. $D_{p}$ is the cut-off distance and $t$, $\gamma$ are adjustable parameters.

For the density function, we choose an exponential form: $f(r)=f_{0} \exp \left(-\beta\left(\frac{r}{a_{0}}-1\right)\right)$. 
The immersion function is chosen to have the following properties : $\mathrm{F}(0)=0, F^{(p)}\left(\rho_{0}\right)=F_{0}^{(p)}(\mathrm{p}=0,1,2)$. Moreover, $F$ has to always be convex for $\rho>\rho_{0}$; if $\rho<\rho_{0}$, this property depends on $F_{0}, F_{0}, F_{0}$ " Thus, the immersion function has a twofold expression:

$\mathrm{F}(\dot{\rho})=\frac{\mathrm{A}}{2 \rho}+\frac{\left[\left(\rho_{0}\right)^{4} \mathrm{~F}_{0}^{\prime \prime}-\mathrm{A} \rho_{0}\right]}{6 \rho^{2}}+\left[\mathrm{F}_{0}^{\prime}+\frac{\mathrm{A}}{6\left(\rho_{0}\right)^{2}}+\rho_{0} \mathrm{~F}_{0}^{\prime \prime} / 3\right] \rho+\mathrm{F}_{0}-\rho_{0} \mathrm{~F}_{0}^{\prime}-\left(\rho_{0}\right)^{2} \mathrm{~F}_{0}^{\prime \prime} / 2-\frac{\mathrm{A}}{2 \rho_{0}}$

if $\rho>\rho_{0}$ ( $\rho_{0}$ is the density over a site of monocrystal at equilibrium).

$\mathrm{F}(\rho)=\rho^{2} \mathrm{~F}_{0}^{\prime \prime} / 2-\left[\mathrm{F}_{0}^{\prime}-\rho_{0} \mathrm{~F}_{0}^{\prime \prime}\right] \rho+\left(\mathrm{F}_{0}-\rho_{0} \mathrm{~F}_{0}^{\prime}+\mathrm{F}_{0}^{\prime \prime}\left(\rho_{0}\right)^{2} / 2\right)\left[1+\left(\frac{\rho}{\rho_{0}}-1\right)^{3}\right]$ otherwise.

The parameter A governs the slope for strong densities. It plays no role in the fitting procedure because all densities appearing there are lower than the equilibrium value. It however influences grain boundaries energies.

The 5 equations expressing the 5 properties mentioned above depend on $F_{0}, f_{0} F_{0},\left(f_{0}\right)^{2} F_{0}{ }^{\prime \prime}, \psi_{0}$ and $\left(f_{0}\right)^{2} \alpha$ linearly. This feature makes it possible to calculate exactly these five parameters so as to reproduce systematically these properties. Strictly speaking, the fitting was performed by a limited manual adjustment of the parameters $\gamma, t, \beta$ et $D_{p}$ in order to get plausible values for the vacancy formation energy as well as the (001) surface energy and structure and energies of several simple tilt grain boundaries. Since it is only a scaling parameter (which nevertheless influences $\alpha, F_{0}{ }^{\prime}$ and $\left.F_{0}{ }^{\prime \prime}\right), f_{0}$ is chosen arbitrarily. It should again be emphasized that for fixed $\gamma, t, \beta$ and $D_{p}$, the physical properties are not modified by varying $f_{0}$ at constant $F_{0}, f_{0} F_{0}{ }^{\prime},\left(f_{0}\right)^{2} F_{0}{ }^{\prime},\left(f_{0}\right)^{2} \alpha$ and $A / f_{0}$. A class of physically equivalent models can thus be generated. Moreover, substraction of a linear function y $\rho$ ( $y$ is a constant) from the immersion function $F(\rho)$ of an element does not modify the configurational energy, if this operation is balanced with the addition of $2 y f(r)$ to the corresponding pair potential.

\section{$3.2 \mathrm{FeAl}$}

The usual method to get an E.A.M. alloy potential rests on the above mentioned properties of the energy of pure elements and on the fact that only $\mathrm{f}_{0}{ }^{\mathrm{Al}} / \mathrm{f}_{0}{ }^{\mathrm{Fe}}$ has a physical meaning for a binary alloy [10]: as in the case of a single element, it is possible to determine equivalent models by varying one $f_{0}$ at constant ratio. Thus we kept $\mathbf{f}_{0}{ }^{\mathrm{Al}}$ equal to $10^{-3}$ and calculated $\mathrm{f}_{0}^{\mathrm{Fe}}$. The $\mathrm{Fe}-\mathrm{Al}$ pair potential is also chosen to be a Morse potential.

The value of $\alpha$ depends on the local environment of an atom. Thus, the fitted value of $\alpha$ for FeAl would be valid strictly speaking only for the perfect stoichiometric monocrystal. Nevertheless, by lack of satisfying as well as easily tractable procedure to calculate this parameter for a given environment, we simply assumed a constant value for the calculation of defect properties (A.P.B. for example), which amounts to regarding $\alpha$ as determined by the global composition. The values obtained that way show that the directionality of bonding is indeed much stronger in the alloy than in the pure elements: the amount of directional bonding is roughly two orders of magnitude higher in the alloy for each element. Direct comparison is allowed by the fact that the scaling parameters $\mathrm{f}_{0}$ are (respectively almost) identical for $\mathrm{Al}$ (for $\mathrm{Fe}$ ) when shifting from components to alloy.

To sum up, $\psi_{\mathrm{FeAl}}, \mathrm{y}_{\mathrm{Al}}, \mathrm{y}_{\mathrm{Fe}}, \alpha_{\mathrm{Al}}, \alpha_{\mathrm{Fe}}$ are determined by solving a linear system so as to reproduce the same five properties as for a pure element. A manual fitting of $f_{\mathrm{Fe}}^{0}, \gamma_{\mathrm{FeAl}}, \mathfrak{t}_{\mathrm{FeAl}}$ and $\mathrm{D}_{\mathrm{pFeAl}}$ was performed to provide correct values of extra defect energies. 


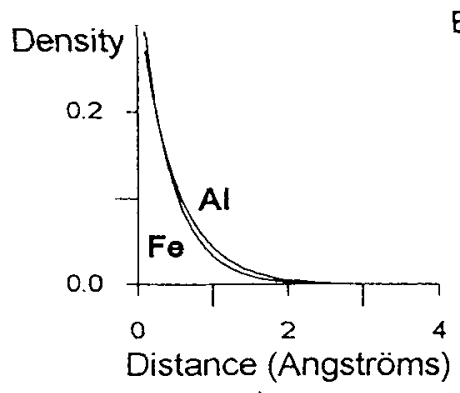

a)

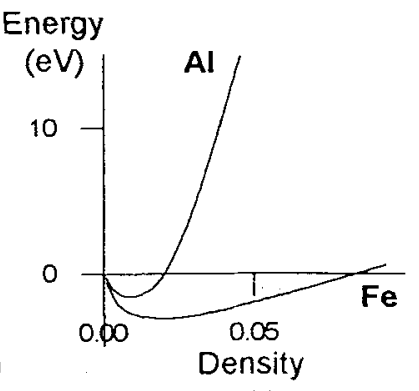

b)

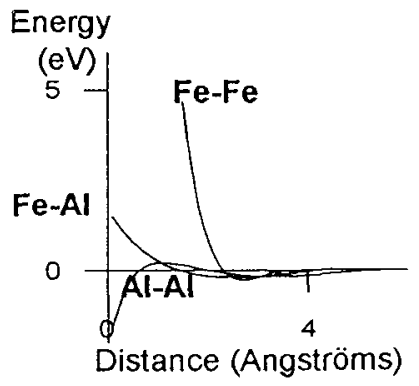

c)

Figure 1: Graphs of the potential used for FeAl: a) density functions, b) immersion functions, c) pair potentials.

\section{RESULTS}

\subsection{Tests of the potential}

For pure elements as well as for $\mathrm{FeAl}$, the experimental values of cohesion energy $[11,12]$, lattice parameter [13] and elastic constants $[14,15]$ are reproduced with a precision better than $0.1 \%$. Other properties are detailed in the following table.

Table 1: Calculated values for pure elements and alloy.

\begin{tabular}{|c|c|c|c|c|c|c|c|c|}
\hline Property & \multicolumn{2}{|c|}{$\mathrm{Al}$} & \multicolumn{2}{|c|}{$\mathrm{Fe}$} & \multicolumn{4}{|c|}{ FeAl } \\
\hline \multirow{3}{*}{$\begin{array}{l}\text { Antiphase boundary } \\
(1-10) 1 / 2[111]\left(\mathrm{mJ} / \mathrm{m}^{2}\right)\end{array}$} & calculated & experim. & calculated & experim & calcu & lated & & \\
\hline & \multirow{4}{*}{$\begin{array}{c}0.6 \\
1280\end{array}$} & \multirow{4}{*}{$\begin{array}{c}0.7[16] \\
1200[17]\end{array}$} & \multirow{4}{*}{$\begin{array}{c}2.0 \\
2220\end{array}$} & \multirow{4}{*}{$\begin{array}{c}1.9[4] \\
2200[4]\end{array}$} & \multicolumn{2}{|c|}{370} & \multicolumn{2}{|c|}{$300[15]$} \\
\hline & & & & & $\begin{array}{l}\mathrm{Al} \\
28\end{array}$ & $\begin{array}{l}\mathrm{Fe} \\
08\end{array}$ & $\mathrm{Al}$ & $\mathrm{Fe}$ \\
\hline (001) surface $\left(\mathrm{mJ} / \mathrm{m}^{2}\right)$ & & & & & 1380 & 2150 & & \\
\hline Antisite defect (eV) & & & & & 0.78 & 0.76 & & \\
\hline
\end{tabular}

Experimental data relative to point or planar defects in FeAl are quite rare. The main available ones concern the vacancy formation energy which must be regarded as an apparent energy taking into account the influence of all types of defects. However, there is some evidence for believing that $\mathrm{Al}$ vacancies are almost inexistant, at least for temperatures below $1000 \mathrm{~K}$. This is the reason why we put down the corresponding measured value to $\mathrm{Fe}$ vacancies. Such an assumption is also backed up by ab initio calculations only providing the Fe vacancy energy, without referring to the Al one.

We also successfully checked the validity of the potential by comparing the relative stabilities of the three classical crystallographic structures. The results are reported below:

Table 2: Stability of metastable structures.

\begin{tabular}{|c|ll|ll|lll|}
\hline Structure & \multicolumn{2}{|c|}{ b.c.c. } & \multicolumn{2}{c|}{ f.c.c. } & \multicolumn{3}{c|}{ h.c.p. } \\
\hline equilibrium values & $\mathrm{a}(\AA)$ & $\mathrm{E}_{\mathrm{coh}}(\mathrm{eV})$ & $\mathrm{a}$ & $\mathrm{E}_{\text {coh }}$ & $\mathrm{a}$ & $\mathrm{c}(\AA)$ & $\mathrm{E}_{\text {coh }}$ \\
\hline $\mathbf{A l}$ & 3.16 & -3.25 & 4.04 & $\mathbf{- 3 . 3 4}$ & 2.67 & 5.42 & -3.32 \\
Fe & 2.86 & $\mathbf{- 4 . 2 9}$ & 3.59 & -4.20 & 2.52 & 4.26 & -4.20 \\
\hline
\end{tabular}


The last test performed up to now concerned $\mathrm{Fe}_{3} \mathrm{Al}$, the equilibrium lattice parameter and formation energy of which were calculated: $5.78 \AA$ (exp. value: $5.7923 \AA[13])$ and $-16.88 \mathrm{eV}$ for $3 \mathrm{Fe}$ and $1 \mathrm{Al}$ (exp value: $-16.86 \mathrm{eV}[12])$.

\subsection{Application to a grain boundary structure}

With this model, we studied by molecular statics the local composition of the $\Sigma 5$ [100] $37^{\circ}$ tilt grain boundary in stoichiometric B2 alloy. We compared the energies of structures differing by rigid translations and composition in the interface plane: we find the energy minimum for the Fe-rich structure (fig. $2 \mathrm{~b}$ ), more stable than the most favourable stoichiometric model (fig. 2a): thus the grain boundary displays an intrinsic (non thermal) enrichment.

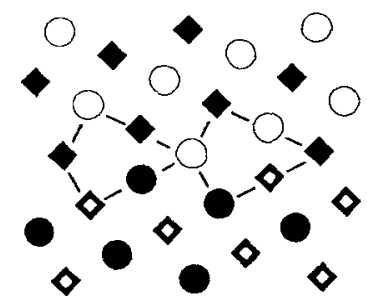

a) $950 \mathrm{~mJ} / \mathrm{m} 2$

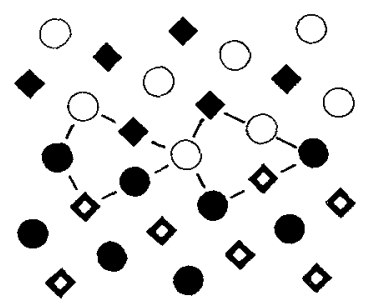

b) $770 \mathrm{~mJ} / \mathrm{m} 2$

Figure 2: Local Fe enrichment on the $\Sigma 5[100] 37^{\circ}$ tilt boundary.

\section{CONCLUSIONS}

We have developed a Modified Embedded Atom Method potential for B2 FeAl alloys. It proved to be quite satisfactory in the description of pure elements and of this compound, characterized by stong directional bonds. The procedure was firstly to fit two separate models for $\mathrm{Fe}$ and $\mathrm{Al}$, and then to determine a cross-potential and an angular parameter specific to the B2 alloy. The negative Cauchy discrepancy could thus be allowed for

The potential gives quite plausible values for defect energies (vacancies, antisites and antiphase boundary), which is an essential feature for future studies of grain boundaries. In this perspective, we tested the model by determining the local enrichment in the $\Sigma 5[100] 37^{\circ}$ tilt grain boundary, and reached the conclusion that an Fe-plane at the interface is needed to get the energy minimum. 


\section{APPENDIX}

Table 3: Interatomic potentials for $\mathrm{Fe}, \mathrm{Al}$ and $\mathrm{FeAl}$ : values of parameters.

\begin{tabular}{|c|c|c|c|c|c|}
\hline & \multicolumn{2}{|c|}{ Pure elements } & \multicolumn{3}{c|}{ FeAl alloy } \\
\cline { 2 - 6 } & $\mathrm{Al}$ & $\mathrm{Fe}$ & $\mathrm{Al}$ & $\mathrm{FeAl}$ & $\mathrm{Fe}$ \\
\hline $\mathrm{f}_{0}$ & $10^{-3}$ & $10^{-3}$ & $10^{-3}$ & & $9.21 .10^{-4}$ \\
$\beta\left(\AA^{-1}\right)$ & 5.8 & 6.0 & & & \\
\hline$\gamma\left(\AA^{-1}\right)$ & 0.3 & 0.9 & & 0.35 & \\
$\mathrm{t}(\AA)$ & 3.45 & 2.8 & & 2.5 & \\
$\psi_{0}(\mathrm{eV})$ & 0.8663 & 1.3152 & & 0.961 & \\
\hline $\mathrm{A}(\mathrm{eV})$ & 0.8 & 0.08 & & & \\
$\mathrm{y}(\mathrm{eV})$ & & & -7.42 & & -84.35 \\
$\alpha(\mathrm{eV})$ & 89 & 1992 & 7467 & & 108064 \\
$\mathrm{~F}_{\text {equitibrium }}(\mathrm{eV})$ & 1.46 & -3.6 & & & \\
$\mathrm{~F}_{\text {'quilibrium }}(\mathrm{eV})$ & 68.2 & -144.6 & & & \\
$\mathrm{~F}^{\prime}{ }_{\text {equilibrium }}(\mathrm{eV})$ & 4647.0 & 2866.9 & & & \\
$\mathrm{D}_{\mathrm{p}}(\AA)$ & 5.65 & 3.5 & & 4.4 & \\
$\mathrm{D}_{\mathrm{d}}(\AA)$ & 5.4 & 4.4 & & & \\
\hline
\end{tabular}

\section{References}

[1] Crimp M.A. and Vedula K., Mat. Sc. and Eng. 78 (1986) 193.

[2] Baskes M. I., Nelson J. S. and Wright A. F., Phys. Rev. B 40 (1989) 6085.

[3] Daw M.S., Phys. Rev. B 39 (1989) 7441.

[4] Finnis M.W. and Sinclair J.E., Phil. Mag. A 50 (1984) 45.

[5] Pettifor D.G. and Aoki M., Phil. Trans. R. Soc. Lond. A 334 (1991) 439.

[6] Stillinger F.H. and Weber T.A., Phys. Rev. B 31 (1985) 5262.

[7] Baskes M. I., Phys. Rev. Lett. 59 (1987) 2666.

[8] Pasianot R., Farkas D. and Savino E. J., Phys. Rev. B 43 (1991) 6952.

[9] Kanzaki H., J. Phys. Chem. Solids 2(1957) 24.

[10] Voter C.T. and Chen D., High Temperature Ordered Interemetallics Alloys, (MRS Symp. Proc., 133, 1989)

[11] Kittel C., Introduction to Solid State Physics (J. Wiley \& Sons, New-York, 1966)

[12] Hultgren et al., Selected Values of the Thermodynamic Properties of Binary Alloys (American Society for Metals, 1973).

[13] W.B. Pearson, Handbook of Lattice Spacings and Structures of Metals (Pergamon Press, 1964).

[14] Simmons G. and Wang H., Single Crystal Elastic Constants and Calculated Aggregate Properties (M.I.T. Press, Boston, 1971).

[15] Fu C.L. and Yoo M.H., Acta Metall. Mater. 40 (1992) 703

[16] Oh D. J. and. Johnson R.A, J. Mat. Res 3 (1988) 471.

[17]. Miedema A.R., Z. Metallk. 69 (1978) 287. 